\title{
Decadal variability in high northern latitudes as simulated by an intermediate-complexity climate model
}

\author{
H. Goosse, ${ }^{1}$ F. M. Selten, ${ }^{2}$ R. J. Haarsma, ${ }^{2}$ J. D. Opsteegh ${ }^{2}$ \\ ${ }^{1}$ Institut d'Astronomie et de Géophysique G. Lemaître, Université Catholique de Louvain, B-1348 Louvain-la-Neuve, Belgium \\ ${ }^{2}$ KNMI, P.O. Box 201, 3730 AE De Bilt, The Netherlands
}

\begin{abstract}
A 2500 year integration has been performed with a global coupled atmospheric ${ }^{-}$-sea-ice- ${ }^{-}$ocean model of intermediate complexity, with the main objective of studying the climate variability in polar regions on decadal time-scales and longer. The atmospheric component is the ECBILT model, a spectral T21 three-level quasi-geostrophic model that includes a representation of horizontal and vertical heat transfers as well as of the hydrological cycle. ECBILT is coupled to the CLIO model, which consists of a primitive-equation free-surface ocean general circulation model and a dynamicthermodynamic sea-ice model. Comparison of model results with observations shows that the ECBILT-CLIO model is able to reproduce reasonably well the climate of the high northern latitudes. The dominant mode of coupled variability between the atmospheric circulation and sea-ice cover in the simulation consists of an annular mode for geopotential height at $800 \mathrm{hPa}$ and of a dipole between the Barents and Labrador Seas for the sea-ice concentration which are similar to observed patterns of variability. In addition, the simulation displays strong decadal variability in the sea-ice volume, with a significant peak at about 18 years. Positive volume anomalies are caused by (1) a decrease in ice export through Fram Strait associated with more anticyclonic winds at high latitudes, (2) modifications in the freezing/melting rates in the Arctic due to lower air temperature and higher surface albedo, and (3) a weaker heat flux at the ice base in the Barents and Kara Seas caused by a lower inflow of warm Atlantic water. Opposite anomalies occur during the volume-decrease phase of the oscillation.
\end{abstract}

\section{INTRODUGTION}

Recent observations performed at high northern latitudes suggest that, compared to previous decades, the present Arctic climate could be characterized by an increase of air temperatures (e.g. Chapman and Walsh, 1993) and a decrease of summer ice extent (e.g. Chapman and Walsh, 1993; Maslanik and others, 1996), ice thickness and multi-year ice cover (Johannessen and others, 1999; Rothrock and others, 1999). In the ocean, a stronger inflow of warm Atlantic waters as well as a less intense halocline in the Eurasian Basin were also noticed in the 1990s (e.g. Dickson, 1998). In the framework of a potential climate change, it is crucial to determine whether those changes are induced by the increase of greenhouse gases in the atmosphere observed during the last 150 years or whether they are elements of the natural climate variability in high latitudes.

Analysis performed on the data collected in polar regions during the last 50 years has helped to clarify this point by providing insight into Arctic climate variability. Although we are still far from a complete understanding, several authors (e.g. Proshutinsky and Johnson, 1997; Slonosky and others, 1997; Mysak and Venegas, 1998; Polyakov and others, 1999; Yi and others, 1999) have identified significant variability on a decadal time-scale in which anomalies of the ice cover and of the atmospheric circulation appear to be strongly linked. In order to explain the observed variability, Mysak and Venegas (1998) have proposed a simple feedback loop. In their mechanism, the ice concentration responds mainly to atmospheric anomalies. However, during a short interval within the cycle, the anomalous ice conditions induce strong heating (or cooling) of the atmosphere in the Greenland Sea, resulting in a rapid shift of the atmospheric state. They also suggest that variability in the Arctic might be coupled to mid-latitude variability, in particular the North Atlantic Oscillation.

In addition, model studies have helped to isolate processes that could be responsible for the observed interannual variability in the Arctic and peripheric seas. For instance, it has been possible to underline the crucial role of surface-albedo and oceanic feedbacks in the evolution of ice volume (e.g. Holland and Curry, 1999) and to show that baroclinic Rossby waves can generate interdecadal variability in the Greenland, Iceland, Norwegian (GIN) Seas (Morales Maqueda and others, 1999). Anomalous ice velocities appear important for the ice-thickness distribution in the Arctic seas (e.g. Flato, 1995; Tremblay and Mysak, 1998). Furthermore, these anomalies influence the ice export through Fram Strait which has a strong impact on the oceanic circulation in the GIN Seas (e.g. Häkkinen, 1993). A link between variability in the Arctic and the thermohaline circulation in the North Atlantic has also been proposed (e.g. Delworth and others, 1997).

By analyzing the results of a 2500 year simulation performed with a coupled atmosphere--sea-ice-ocean model of intermediate complexity, the present study intends to provide further insight into the decadal variability in the Arctic. The first goal is to identify variables or modes which display strong decadal variability in the simulation. The second goal is to analyze the atmospheric and sea-ice patterns associated with this decadal variability and compare them to the observed 
modes of variability. The model is described in section 2. In section 3, the model climatology is compared to observations. The major patterns of coupled variability between the atmospheric circulation and ice concentration in the Northern Hemisphere as well as the decadal variability of the total ice volume in the Northern Hemisphere are studied in section 4. This is followed by concluding remarks (section 5).

\section{MODEL DESGRIPTION}

ECBILT-CLIO is a three-dimensional coupled atmosphereocean-sea-ice model. The atmospheric component is ECBILT2 (Opsteegh and others, 1998; Selten and others, 1999), a global spectral quasi-geostrophic model, truncated at T21, with simple parameterizations for the diabatic heating due to radiative fluxes, the release of latent heat and the exchange of sensible heat with the surface. The model simulates the midlatitude planetary and synoptic-scale circulations well. Due to the quasi-geostrophic approximation, model integrations are two orders of magnitude faster than atmosphere general circulation models. However, the model cannot be used to study tropical variability and tropical-extratropical interactions. The radiative-flux calculations are based on a linearization of the radiation code of the ECHAM4 model (Van Dorland and others, in press). The model contains a full hydrological cycle which is closed over land by a bucket model for soil moisture. Each bucket is connected to a nearby ocean gridpoint to define the river runoff. Accumulation of snow over land occurs in case of precipitation when the land temperature is below zero. As the model does not include an interactive ice-sheet component, Greenland and Antarctic ice sheets are assumed to be in equilibrium. Precipitation, sublimation and melting are computed at the ice-sheet surface. The difference between those terms, integrated over each ice sheet, is compensated for by iceberg calving in order to achieve a mass balance. Those icebergs are discharged into the ocean where they melt instantaneously.

The CLIO model (Goosse and Fichefet, 1999; Goosse and others, 1999) comprises a primitive-equation, free-surface ocean general circulation model coupled to a thermodynamic-dynamic sea-ice model. The ocean component includes a relatively sophisticated parameterization of vertical mixing in the ocean as well as a parameterization of dense water flow down topographic features. A three-layer model, which takes into account sensible- and latent-heat storage in the snow-ice system, simulates the changes of snow and ice thickness in response to surface and bottom heat fluxes. In the computation of ice dynamics, sea ice is considered to behave as a viscous-plastic continuum. The horizontal resolution of $\mathrm{CLIO}$ is $3^{\circ}$ in latitude and longitude and there are 20 unevenly spaced vertical levels in the ocean.

ECBILT and CLIO are coupled with the OASIS software (Terray and others, 1998). The two models have different grids. Nevertheless, every atmospheric surface gridcell can contain an arbitrary fraction of open ocean (or leads), sea ice and land surface. It is therefore possible to achieve an exact matching of the area occupied by these three types of surface in the two models in order to conserve the heat and mass exchanged at the interface. There is no local flux correction in ECBILT-CLIO. However, the model systematically overestimates the precipitation over the Atlantic and Arctic Oceans (Opsteegh and others, 1998) with potential consequences for the stability of the thermohaline circulation as
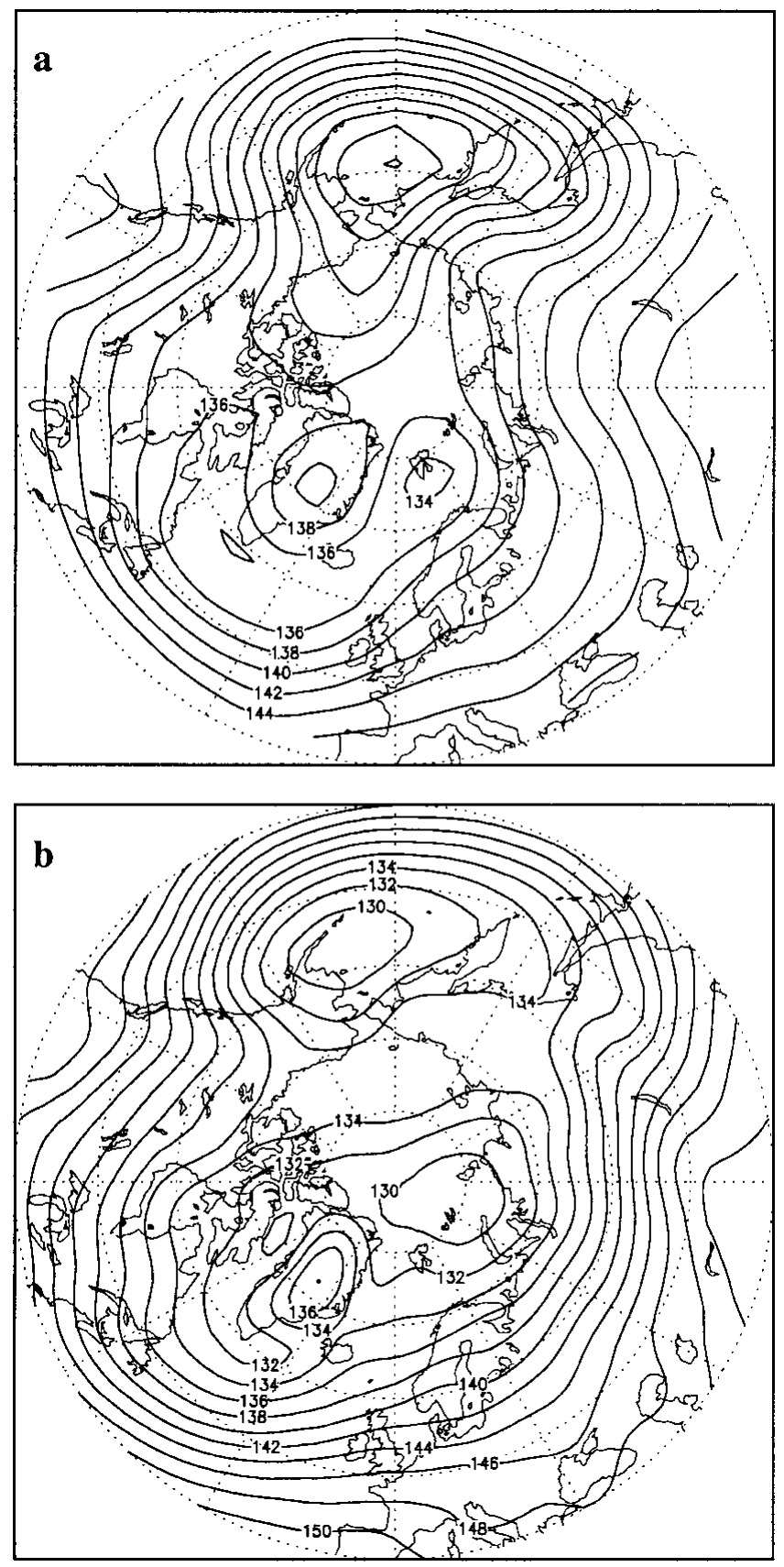

\begin{abstract}
Fig. 1.Winter mean (October-March) 800 hPa geopotential height in the Northern Hemisphere (a) simulated by the model and ( $b$ ) based on NCEP-NCAR re-analyses. Contour interval is 2 dam.
\end{abstract}

well as for the mass balance of the Arctic snow-sea-ice system. As a consequence, it has been necessary to artificially reduce the precipitation by $10 \%$ over the Atlantic and by $50 \%$ over the Arctic basins (defined here as the oceanic area north of $68^{\circ} \mathrm{N}$ ). The corresponding water is redistributed homogeneously over the North Pacific, a region where the model precipitation is too weak.

\section{GLIMATOLOGY}

The initial oceanic state for the coupled simulation results from a 10 year long spin-up experiment forced by climatological atmospheric fields and using a strong relaxation of salinity and temperature to Levitus' (1982) observations at all depths. For the atmosphere, the initial state has been chosen 

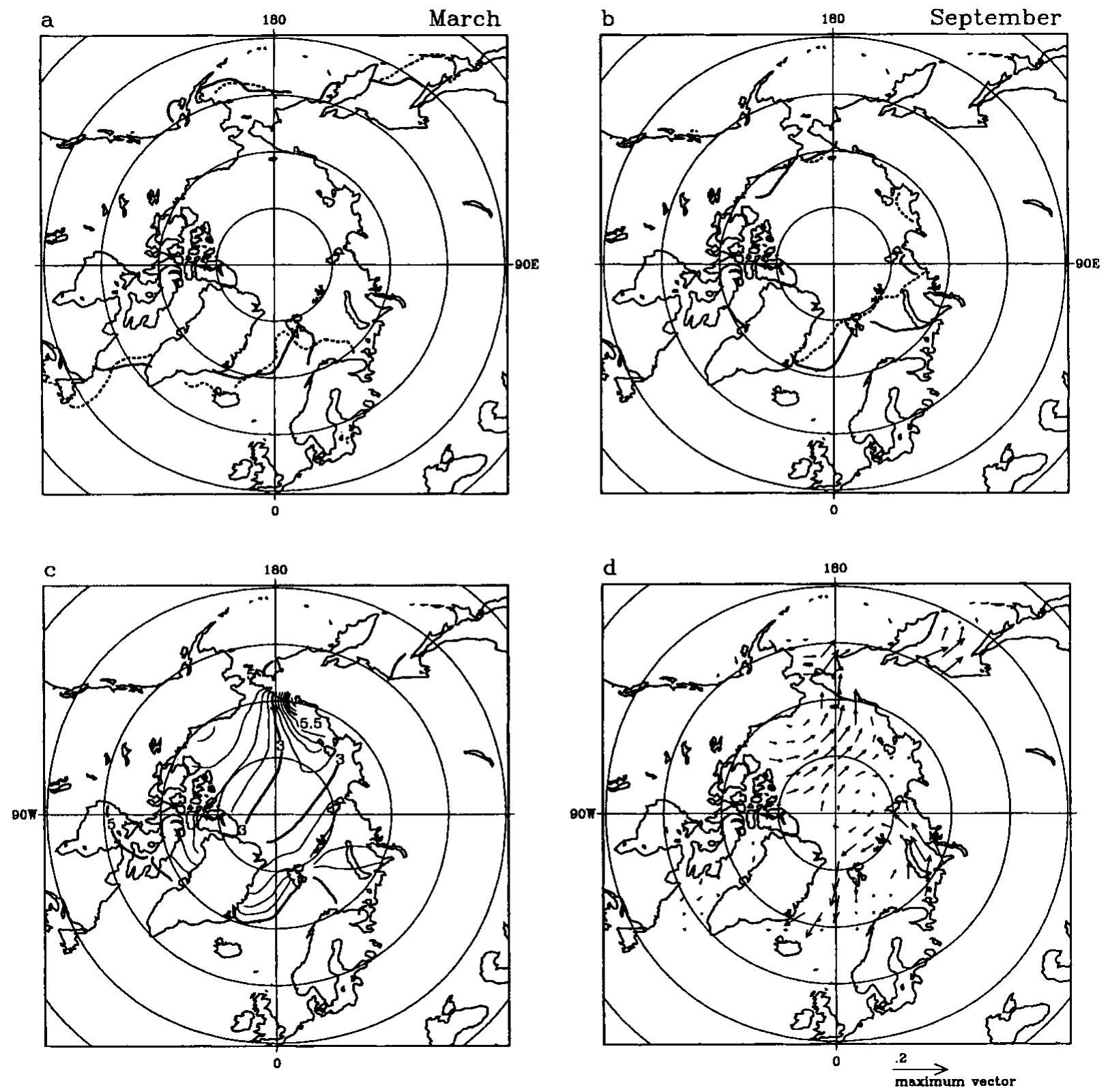

Fig. 2. The simulated ( solid line) and observed (dashed line) (Gloersen and others, 1992) position of the ice edge defined as the $15 \%$ ice concentration in (a) March and (b) September. (c) Winter mean (October-March) ice thickness. Contour interval is $0.5 \mathrm{~m}$. (d) Winter mean (October-March) ice velocity (in $\mathrm{m} \mathrm{s}^{-1}$ ).

as the end of a 10 year integration of the ECBILT model forced by prescribed sea-surface temperature (SST). After 2500 years of integration, the coupled model has reached a quasi-equilibrium. For example, the temperature drift in the bottom ocean layer at this moment is $<2 \times 10^{-3}{ }^{\circ} \mathrm{C}$ per century. In this section, the climatology of the last 500 years of the simulation is briefly discussed.

The globally averaged annual mean SST simulated by the model is $0.8^{\circ} \mathrm{C}$ higher than Levitus' (1982) observations. Locally, the error can be much larger, particularly in the Southern Ocean $\left(4^{\circ} \mathrm{C}\right.$ too warm in zonal mean at $\left.55^{\circ} \mathrm{S}\right)$ and in the eastern tropical Pacific $\left(4^{\circ} \mathrm{C}\right.$ too warm close to the eastern boundary). On the other hand, the simulated temperature is up to $3^{\circ} \mathrm{C}$ too low in the Pacific and Atlantic Oceans between $25^{\circ} \mathrm{N}$ and $50^{\circ} \mathrm{N}$. The large-scale distribution of sea-surface salinity is relatively well represented, partly thanks to the correction applied to the precipitation. Nevertheless, the Atlantic is too fresh by about $0.5 \mathrm{psu}$ (practical salinity units) in annual mean.
Below $1000 \mathrm{~m}$ depth, the oceanic temperature is slightly higher (up to $0.5^{\circ} \mathrm{C}$ in zonal mean) and the salinity is slightly lower (up to 0.1 psu in zonal mean) than the observations except in the deep Southern Ocean and Arctic where the error reaches $1.5^{\circ} \mathrm{C}$ and $0.3 \mathrm{psu}$ in zonal mean. $15 \mathrm{~Sv}$ of North Atlantic Deep Water (NADW) are exported at $30^{\circ} \mathrm{S}$ out of the Atlantic Ocean between 1000 and $3500 \mathrm{~m}$, while $6 \mathrm{~Sv}$ of Antarctic Bottom Water flow northward at the same latitude below the NADW. Those values are within the range of the current estimates of the intensity of the thermohaline circulation (e.g. Schmitz, 1995).

The winter mean (October-March) geopotential height at $800 \mathrm{hPa}(\phi 800)$ simulated by the model in the Northern Hemisphere is compared to U.S. National Centers for Environmental Prediction-U.S. National Center for Atmospheric Research (NCEP-NCAR) re-analysis (Kalnay and others, 1996) in Figure 1. The model reasonably simulates the shape and position of the Aleutian and Icelandic lows, although the latter is slightly shifted southward compared to observations. 
This induces realistic wind direction over the North Pacific and the North Atlantic. Nevertheless, the meridional gradient of geopotential height is significantly too low over the Atlantic. Furthermore, the extent of the Aleutian low over the Arctic is overestimated in the model. North of the Alaskan and Canadian coasts, this results in wind directions opposite to the observed ones. In the Southern Hemisphere, the winter circulation is also weaker than observed, but the zonal asymmetries of the flow are rather well simulated.

In the Northern Hemisphere, the sea-ice concentration is in good agreement with the observations of Gloersen and others (1992) (Fig. 2a and b). In March, the ice extent is slightly underestimated in the Labrador, Iceland and Okhotsk Seas, and is overestimated in the Barents Sea. In September, the model overestimates the ice extent in the Greenland and Barents Seas and in Baffin Bay, while the simulated ice concentration is too low north of Canada. Because of the wrong wind direction in a large part of the central Arctic (see above), sea ice accumulates in the East Siberian Sea, with maximum ice thickness up to $6 \mathrm{~m}$ in winter (Fig. 2c and d). This is opposite to observations (Bourke and McLaren, 1992) which show maximum ice thickness north of the Canadian Archipelago. Similar errors on the position of the maximum ice thickness have also been observed in other coupled atmosphere-ocean-ice models (e.g. Weatherly and others, 1998). In the Barents and Kara Seas, the simulated ice thickness reaches a maximum of $2.5 \mathrm{~m}$ in winter. This value is within the range of observational estimates, although probably on the high side. The ice velocities in the Eurasian Basin are more reasonable than north of Alaska, with a relatively well-developed transpolar drift which transports ice from the Siberian coast towards Fram Strait. The annual mean southward export there is $8.8 \times 10^{-2} \mathrm{~Sv}$ in the model, which is slightly higher than the more recent estimates (e.g. $7.5 \times 10^{-2}$ Sv in Kwok and Rothrock, 1999).

The agreement between model and observations is much weaker in the Southern Hemisphere. Because the oceanic and atmospheric temperatures are too high there, the ice extent is significantly underestimated. The simulated ice area is about $1 \times 10^{12} \mathrm{~km}^{2}$ in summer and $8 \times 10^{12} \mathrm{~km}^{2}$ in winter, while the observed values are $2 \times 10^{12} \mathrm{~km}^{2}$ and $15 \times 10^{12} \mathrm{~km}^{2}$, respectively (Gloersen and others, 1992).

\section{VARIABILITY IN THE HIGH NORTHERN LATITUDES}

In addition to the comparison between observed and simulated mean climate, it is also useful to describe the major patterns of variability produced by the model. In this context, the links between fluctuations of sea-ice cover and atmospheric circulation have been analyzed by performing a singular value decomposition (SVD) between winter mean geopotential height at $800 \mathrm{hPa}$ and winter mean seaice concentration for the last 500 years of the simulation. This technique allows patterns to be extracted that optimally describe the covariance structure of the two variables (for more details about the SVD, see Bretherton and others, 1992). The first SVD mode, which contributes to $41 \%$ of the square covariance, is plotted in Figure 3. The atmospheric pattern (Fig. 3a) is an annular mode with negative values over the polar regions and positive ones centred over the North Pacific and Atlantic at about $45^{\circ} \mathrm{N}$. It is nearly identical to the first empirical orthogonal function (EOF) of $\phi 800$
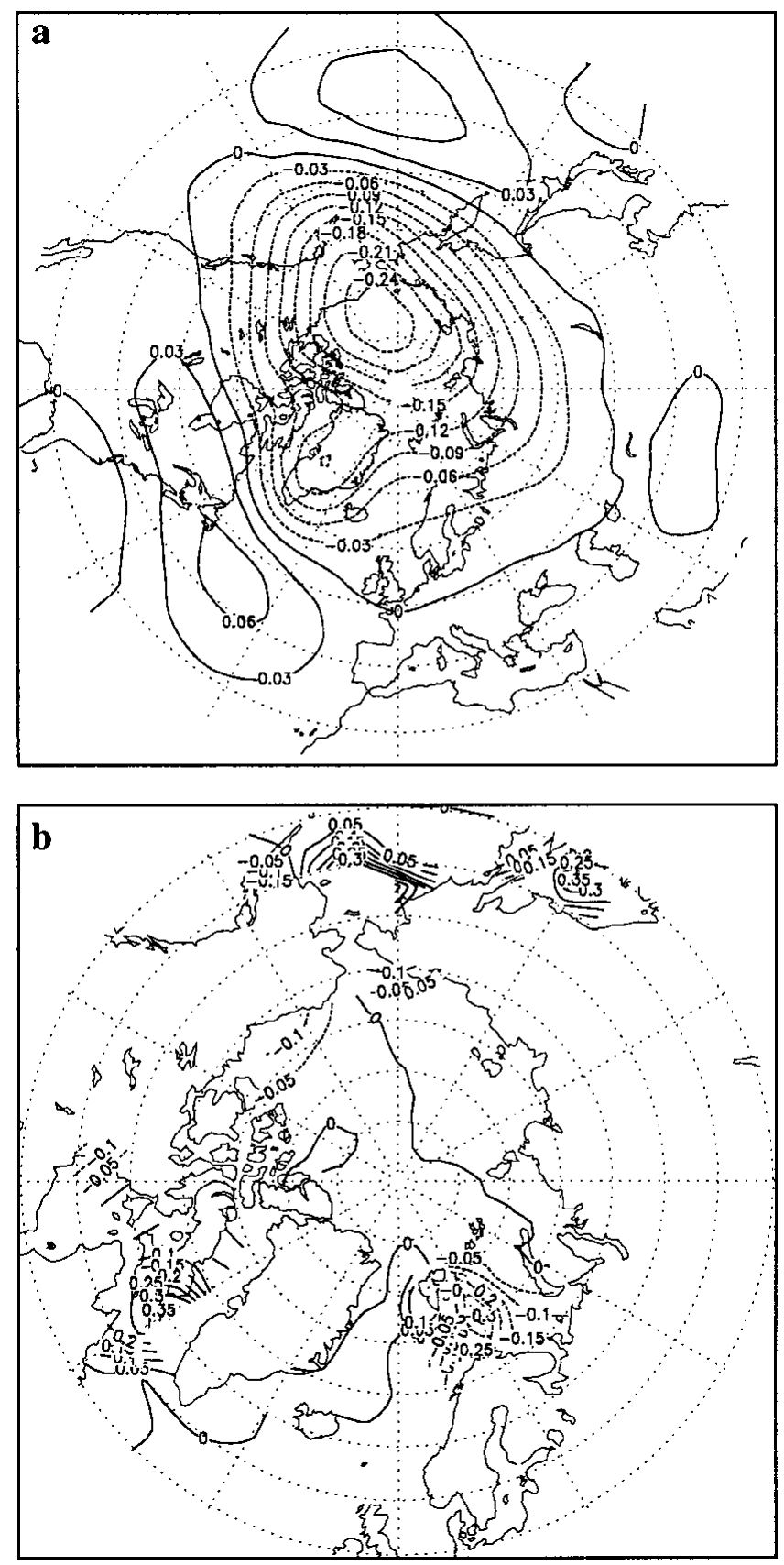

Fig. 3. First SVD mode of winter mean $800 \mathrm{hPa}$ geopotential height and sea-ice concentration for the last 500 years of the simulation. (a) ф800 pattern; (b) sea-ice concentration pattern.

which accounts for $39 \%$ of the $\phi 800$ variance. The ice-concentration pattern (Fig. $3 \mathrm{~b}$ ) presents a dipole between the Labrador Sea and the Barents Sea as well as a signal in the North Pacific of the same sign as the one in the Labrador Sea. The correlation between these two patterns is 0.67 .

This first SVD mode is close to that obtained from observed data by Yi and others (1999) using the same technique. The major difference in the atmospheric pattern is a minimum centred over the Beaufort Sea in our simulation and near the Greenland Sea in Yi and others (1999). For the ice concentration, Yi and others (1999) also obtained a dipole between the Labrador and Nordic Seas (as in Walsh and Johnson, 1979; Deser and others, 2000). In contrast to our results, however, the Greenland Sea displays a strong signal of the same sign as in the Barents Sea in their study. In addition, it must be stressed that the $\phi 800$ pattern (Fig. $3 \mathrm{a})$ is close to that associated with the Arctic Oscillation 


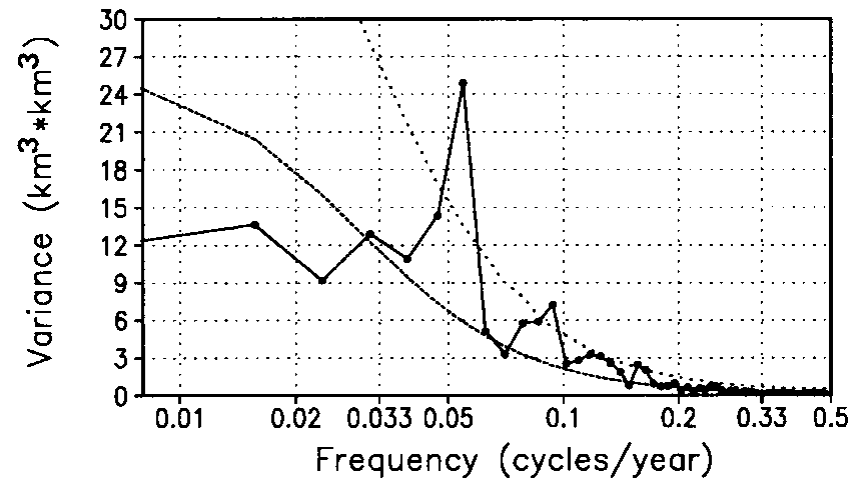

Fig. 4.Variance spectrum of the annual mean sea-ice volume in the Northern Hemisphere $\left(\mathrm{km}^{3} \times \mathrm{km}^{3}\right)$ (solid line). The dashed line represents a red-noise fit determined from the autocorrelation coefficient at lag-1year of the analyzed time series. The thin dotted line represents the 99\% confidence level estimated from a Monte Carlo simulation of $10^{5}$ firstorder autoregressive process time series using parameters estimated from the autocorrelation coefficients and total variances of the analyzed time series.

(AO) which has been identified as the dominant mode of variability in the Northern Hemisphere (Thompson and Wallace, 1998).

In agreement with previous studies (e.g. Yi and others, 1999; Deser and others, 2000), the $\phi 800$ and sea-ice concentration patterns are coherent with a mechanism in which the atmosphere drives the sea-ice fluctuations. For instance, when the winds are more southward (northward) in the Labrador Sea, bringing more ice and cold air, the sea-ice concentration tends to be higher (lower) there. Similar reasoning is valid for the Barents Sea.

In order to analyze the temporal evolution of the patterns identified in Figure 3, a spectral analysis of the amplitude of the $\phi 800$ and ice-concentration modes has been performed. These spectra are basically white for the $\phi 800$ and red for the sea-ice concentration. This means that these modes display variability at all time-scales, but, contrary to what is suggested by Yi and others (1999), they do not have a peak at decadal time-scale in our simulation.

The second SVD mode between $\phi 800$ and sea-ice concentration, which contributes to $16 \%$ of the square covariance, is mainly restricted to the North Pacific and is associated with shifts of the Aleutian low (not shown). This mode is similar to the second SVD of Yi and others (1999). As already noticed for our first SVD mode, the second one does not present a peak at a decadal time-scale, although a marginally significant peak (significant at 95\% level but not at $99 \%$ ) is found at a time-scale of about 70-90 years.

On the other hand, the simulated total ice volume in the Northern Hemisphere presents a strong peak at a period of about 18 years, as shown in its variance spectrum for the last 500 years of the simulation (Fig. 4). This peak is significantly different from a red-noise process at $99 \%$ confidence level (note however that a red-noise process seems not to be a very good fit for the total sea-ice volume). In addition, the same analysis performed over years 1000-1500 and 15002000 of the simulation also presents a significant peak between 15 and 20 years. The range of variation (twice the amplitude) of the ice volume during one period of this oscillation is about $6 \times 10^{3} \mathrm{~km}^{3}$, i.e. $25 \%$ of the mean value. This

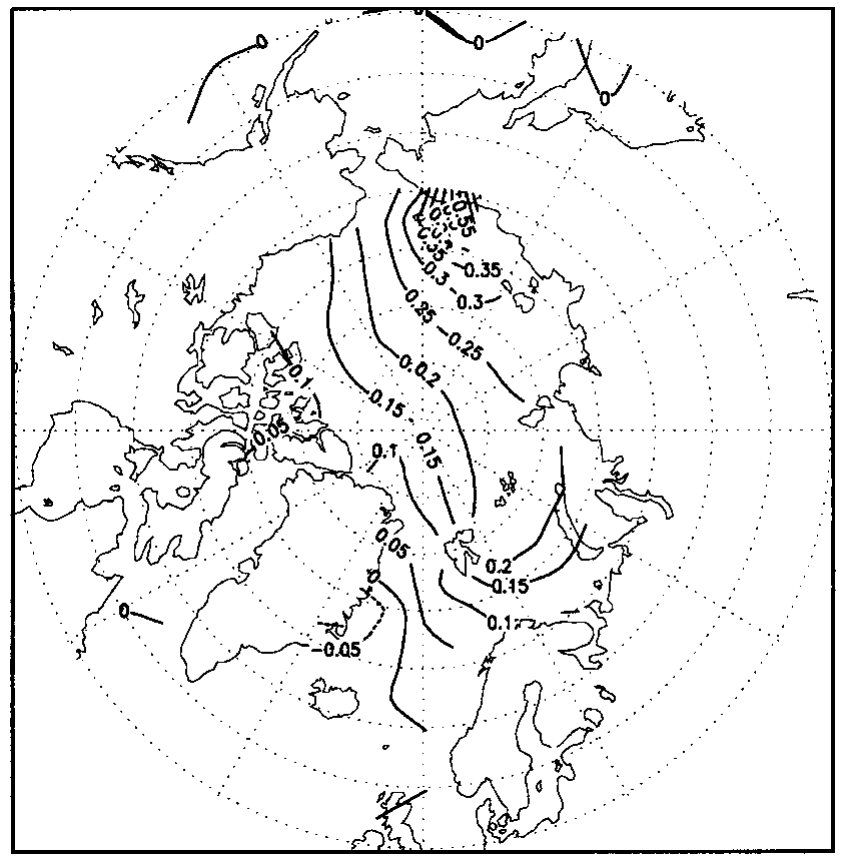

Fig. 5. Winter mean (October-March) sea-ice thickness regressed upon the annual mean sea-ice volume in the Northern Hemisphere. The change in sea-ice thickness related to one standard deviation change in sea-ice volume is shown. Contour interval is $0.05 \mathrm{~m}$.

18 year signal is also apparent in the annual mean ice extent, but the peak is less pronounced, even though it is still different from a red-noise process at the $99 \%$ level. The range of variation in ice extent is $<1 \times 10^{12} \mathrm{~km}^{2}$ (compared to the 500 year mean of $10.9 \times 10^{12} \mathrm{~km}^{2}$ ). This means that the oscillation has a smaller relative impact on the ice extent than on the ice volume.

The changes in Northern Hemisphere ice volume are accompanied by minor differences in ice thickness in the North Pacific, the Labrador Sea and the Greenland Sea (which is the only region where ice thickness decreases when the total ice volume increases). In the central Arctic, the icethickness increase related to a change of one standard deviation of the total ice volume ranges from $10 \mathrm{~cm}$ north of Greenland to $50 \mathrm{~cm}$ off the Siberian coast (Fig. 5). This mimics the model climatological mean ice-thickness distribution, with an anomaly corresponding to about $10 \%$ of the mean. The relative changes are stronger north of Alaska and in the Barents Sea where the $15-20 \mathrm{~cm}$ increase in ice thickness (Fig. 5) corresponds to about $20 \%$ of the mean value. Ice concentration and ice extent also tend to be higher when the ice volume is high. In summer, a general increase in ice extent is noticed in nearly all regions. In addition, the area covered by leads decreases in the central Arctic. In winter, the increase in ice extent is mainly located in the Barents Sea. The changes in the perennially ice-covered regions are weaker since the concentration there is always very close to unity in this season in the model. As already noticed for the ice thickness, the only regions where the ice concentration decreases when total ice volume is high is the Greenland Sea. This decrease is stronger in winter but is noticeable all year long. It is interesting to note that the second EOF of the observed sea-ice concentration displays a dipole between the Barents Sea and Greenland Sea (personal communication from A. Armstrong, 2000) which 


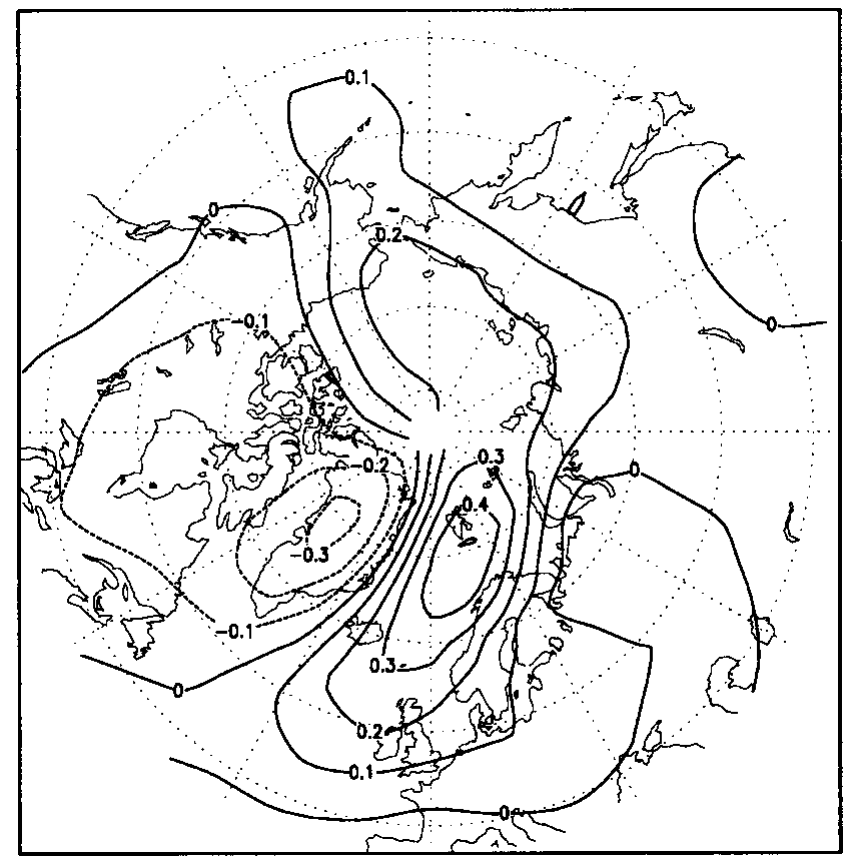

Fig. 6. Changes in winter mean (October-March) $800 \mathrm{hPa}$ geopotential height related to one standard deviation change in the annual mean sea-ice volume in the Northern Hemisphere at lag-4 years (geopotential height leads). Before the analysis, a 5 year running mean was applied to the fields. Contour interval is $0.1 \mathrm{dam}$.

bears some similarities to the pattern associated with the volume change in our simulation.

The first candidate that could explain the variations of sea-ice volume described above is a change of the southward ice export of Arctic sea ice. The transport through Fram Strait constitutes the major contribution to this export. In order to evaluate its impact, the anomalous ice export through Fram Strait has been integrated over time intervals corresponding to a transition from a low ice volume to a high ice volume (and the opposite). The time intervals taken into account in this computation must have a duration of about half the period of the oscillation (7-12 years) and display a change in ice volume exceeding a threshold value. The results are not very sensitive to the time interval or the threshold value used, providing that the latter is higher than $1 \times 10^{12} \mathrm{~km}^{2}$. Averaged over all the events retained, the computation always yields a contribution of the ice export between $25 \%$ and $35 \%$ of the total sea-ice volume changes, confirming the importance of this transport already suggested by various authors (e.g. Häkkinen, 1993).

The annual mean ice export through Bering Strait is at least an order of magnitude smaller than the export through Fram Strait. This is also the case for the export off the Barents Sea into the North Atlantic, although its variability is nearly as high as that of the export through Fram Strait in the model. Nevertheless, an analysis similar to that described above for Fram Strait transport reveals that the anomalous export out of the Barents Sea contributes to $-2 \%$ to $-5 \%$ of the changes of ice volume. This means that the variability of the transport there slightly counteracts the effect of the anomalous ice transport through Fram Strait.

The changes of geopotential height 4 years before the ice volume reaches its maximum (Fig. 6) are consistent with a smaller ice export through Fram Strait during the periods of



Fig. 7. Changes in annual mean surface air temperature related to one standard deviation of the annual mean sea-ice volume in the Northern Hemisphere at lag-4years (air-temperature leads) which corresponds to the maximum correlation between the fields. Before the analysis, a 5 year running mean was applied to the fields. Contour interval is $0.1 \mathrm{~K}$.

ice-volume increase since the northerly winds there are reduced. At the same time, the winds tend to increase the southward ice transport in the Kara and Barents Sea. The more frequent northerly winds in the Barents Sea also bring cold air to the area. These two processes contribute to the increase in ice extent and thickness in this region (see Fig. 5). The opposite phenomenon occurs in the Greenland Sea where the ice cover decreases. The increase in ice volume is also associated with more anticyclonic winds over the whole Arctic (Fig. 6), but the changes in wind (and ice) velocity there are weaker than in the Barents, Kara and Greenland Seas. South of $60^{\circ} \mathrm{N}$, the changes are significantly weaker.

A budget analysis of the time evolution of ice volume reveals that in situ freezing and melting rates contribute nearly equally to the fraction of the ice-volume changes not accounted for by the anomalous ice export. An important cause of this modification of melting/freezing rates is the allyear-long atmospheric cooling at high latitudes, which leads by about 4 years the maximum in ice volume (Fig. 7). This cooling is due to the lower inflow of relatively warm air of Atlantic origin through the Barents Sea (see Fig. 6). The signal is maximal in the Barents Sea, with a decrease of annual mean temperature of $1^{\circ} \mathrm{C}$ per standard deviation of ice volume. In the central Arctic, the cooling is of about $0.4^{\circ} \mathrm{C}$. In contrast, the temperature increases north of Iceland as well as in the North Atlantic, but the changes there are relatively weak, partly because of the smaller variability of temperature in ice-free regions due to the higher heat capacity of the ocean. The cooling is affected by the well-known temperature-albedo feedback, in which colder temperatures induce less ice melting and thus a higher albedo, which amplifies the initial cooling. The decrease in open-water area that takes place concurrently with the increase in ice volume also contributes to less absorption of solar radiation in the 
ice- ocean system. Averaged over the summer months (JuneAugust), this decrease of solar absorption reaches $2 \mathrm{~W} \mathrm{~m}^{-2}$ per standard deviation of the ice volume north of Alaska and in the Barents Sea, and about $1 \mathrm{~W} \mathrm{~m}^{-2}$ close to the North Pole.

In addition to the lower air temperature and solar heatflux absorption during the period of ice-volume increase, the lower oceanic heat flux at the ice base contributes to the modification of freezing and melting rates noticed in the model. The changes occur principally in the Barents and Kara Seas, where the smaller inflow of Atlantic waters causes a decrease of the annual mean flux of $1-2 \mathrm{~W} \mathrm{~m}^{-2}$ per standard deviation of ice volume (lag -4 years). This reduction of Atlantic inflow in the Barents Sea is consistent with the lower northward wind stress there (Fig. 6) but could also be due to a thermohaline effect. On the other hand, in the central Arctic, the oceanic heat flux at the ice base (excluding the contribution from leads) is virtually unchanged.

A precise comparison of the model decadal variability with observations is not feasible because of lack of data, particularly on ice thickness and ice volume which, as we have shown, display the most significant signal in our simulation. Nevertheless, the phases of ice-volume increase and decrease in the model correspond relatively well to the anticyclonic circulation regime (ACCR) and the cyclonic circulation regime (CCR) described by Proshutinsky and Johnson (1997). During the ACCR, the atmospheric pressure is higher in the central Arctic (cf. Fig. 6), and the air surface temperature is colder, the differences of temperature being larger in regions close to the North Atlantic than in regions close to the Pacific Ocean (cf. Fig. 7). The observed transition between regimes occurs every 5-7 years, i.e. a 10-15 year period (Proshutinsky and Johnson, 1997). This is faster than in our simulation, although 50 years of observations is a relatively short period to give a precise time-scale. Furthermore, based on the results of an ice- ${ }^{-}$ocean model forced by typical ACCR conditions, Polyakov and others (1999) suggest a lower export of sea ice through Fram Strait and a lower inflow of Atlantic waters in the Barents Sea during ACCR years. Just the opposite occurs during CCR years. These authors (p. 25,784) estimate from their simulations that the difference of the total ice mass between the two regimes is $28 \%$, which is remarkably close to the results of our model.

\section{GONGLUSIONS}

The comparison of model climatology with observations has proved that the model can simulate reasonably well the mean climate at high northern latitudes. Some problems remain such as a wrong ice-thickness distribution in the central Arctic. Nevertheless, the agreement between model and observation is sufficient to deduce valuable information about the behaviour of the atmosphere-ice- ${ }^{-}$ocean system from model results. On the other hand, the model is significantly too warm at high southern latitudes, resulting in a strong underestimation of the ice extent. In order to solve this problem, a more realistic parameterization of the effects of sub-gridscale eddies has been introduced in the model (Gent and McWilliams, 1990). The first results are encouraging, although the Southern Ocean is still too warm.

The simulated dominant mode of variability of the atmospheric circulation in the Northern Hemisphere is an annular mode similar to the Arctic Oscillation described by Thompson and Wallace (1998). This atmospheric mode is associated with a dipole of sea-ice concentration between the Labrador and Barents Seas. This is close to the observed pattern except that the model cannot reproduce the strong signal observed in the Greenland Sea. The model annular mode has no preferred time-scale. Besides, the total sea-ice volume in the Northern Hemisphere displays decadal variability with a time-scale of about 18 years. The signal is also apparent on the ice extent but with a lower amplitude.

During the phase of ice-volume increase, about $30 \%$ of the volume changes are due to anomalous ice export through Fram Strait. The remaining part is caused by higher ice formation and lower ice melting in the Arctic, which are induced by a general decrease of air temperatures all year long and the associated increase in surface albedo. Furthermore, the inflow of warm Atlantic waters in the Barents Sea is low during this period, generating reduced oceanic heat flux at the ice base in the Barents and Kara Seas. These findings, in addition to the more anticyclonic (cyclonic) atmospheric circulation over the Arctic in the phase of volume increase (decrease), make the decadal variability simulated by the model quite similar to that described by Proshutinsky and Johnson (1997) and Polyakov and others (1999).

Although the annular mode $(\mathrm{AO})$ is the dominant mode of atmospheric variability, it is a pattern confined to polar regions that is associated with the decadal variability of the sea-ice volume. Similar patterns, presenting a relatively low spatial extent and a strong meridional flow in the Nordic Seas, have recently been correlated with multi-decadal variability of SST in the Denmark Strait in the simulation of Delworth and others (1997), with the sea-ice transport at Fram Strait (Hilmer and Jung, 2000) and with the occurrence of cold-air outbreak in the Nordic seas (Skeie, 2000).

The North Atlantic Oscillation (NAO), simulated in a previous version of the model using a simpler ice--ocean model, is analyzed in Selten and others (1999). This model NAO, which has been identified as the second SVD mode between geopotential height at $800 \mathrm{hPa}$ and SST in the Atlantic, describes a change in strength of the climatological atmospheric jet over the eastern part of the basin. In this respect it is similar to the observed NAO. Nevertheless, the simulated pattern is southward-shifted by about $10^{\circ}$ as compared to its observed counterpart (Selten and others, 1999) which is related to the southward-shifted climatological position of the Icelandic low. The present model version displays a similar mode of variability but with different temporal characteristics: the peak at a time-scale of 16-18 years of Selten and others (1999) has disappeared while a peak at a time-scale of about 8 years is noticed in our simulation. We were not able to identify strong links between this model NAO and the decadal variability of the ice volume. Nevertheless, the relationship between NAO and the ice circulation in the Arctic is complex (e.g. Hilmer and Jung, 2000), and the connections between decadal variability at high and mid-latitudes need more work.

Another point that will be investigated in the near future is the understanding of the processes which are responsible for the preferred decadal variability of the ice volume and which determine the 18 year time-scale. Mysak and Venegas (1998) suggest that ice anomalies in the Greenland Sea in periods of low ice cover could induce an intensification of the Icelandic low and then modify the atmospheric circulation over the Arctic. This would induce an increase of the ice concentration there and thus provide the negative feedback necessary to sustain the oscillation. The time-scale is 
assumed to be imposed by the formation and propagation of ice anomalies in the Arctic basin. We plan to perform further analyses of model results as well as sensitivity studies in order to ascertain whether such processes are important for our oscillation or whether an alternative explanation is needed

\section{ACKNOWLEDGEMENTS}

We wish to thank B. Tartinville, H. Renssen and M. A. Morales Maqueda for their careful reading of the manuscript and constructive criticism. The comments and suggestions of two anonymous referees are very much appreciated. H. Goosse is Senior Research Assistant at the National Fund for Scientific Research (Belgium) and acknowledges the KNMI for a grant during his stay at KNMI in March-August 1998. F. Selten was supported by the Dutch National Research Programme on Global Air Pollution and Climate Change, registered under No. 951208, titled, "Climate Variability on Decadal Timescales". R. Haarsma was supported by the Scale INTeraction EXperiments (SINTEX) project of the European Commission, contract ENV4-CT98-0714. This study was carried out within the scope of the Global Change and Sustainable Development Programme (Belgian State, Prime Minister's Services, Federal Office for Scientific, Technical, and Cultural Affairs, contract CG/DD/09A), the Environment and Climate Programme (European Commission, contract ENV4-CT970643) and the Concerted Research Action 097/02-208 (French Community of Belgium, Department of Education, Research, and Formation). All support is gratefully acknowledged.

\section{REFERENCES}

Bourke, R. H. and A. S. McLaren. 1992. Contour mapping of Arctic basin ice draft and roughness parameters. f. Geophys. Res., 97 (C11), 17,715-17,728.

Bretherton, C. S., C. Smith and J. M. Wallace. 1992. An intercomparison of methods for finding coupled patterns in climate data. 7. Climate, 5(6), 1993-2011.

Chapman, W. L. and J. E. Walsh. 1993. Recent variations of sea ice and air temperature in high latitudes. Bull. Am. Meteorol. Soc., 74(1), 33-47.

Delworth, T. L., S. Manabe and R. J. Stouffer. 1997. Multidecadal climate variability in the Greenland Sea and surrounding regions: a coupled model simulation. Geophys. Res. Lett., 24(3), 257-260.

Deser, C., J. E. Walsh and M. S. Timlin. 2000. Arctic sea ice variability in the context of recent atmospheric circulation trends. 7. Climate, 13 (3), 617-633.

Dickson, R. R. 1998. All change in the Arctic. Nature, 397(6718), 389-391.

Flato, G. M. 1995. Spatial and temporal variability of Arctic ice thickness. Ann. Glaciol., 21, 323-329.

Gent, P. R. and J. C. McWilliams. 1990. Isopycnal mixing in ocean circulation models. 7. Phys. Oceanogr., 20(1), 150-155.

Gloersen, P., W. J. Campbell, D. J. Cavalieri, J. C. Comiso, C. L. Parkinson and H.J. Zwally. 1992. Arctic and Antarctic sea ice, 1978-1987: satellite passive-microwave observations and analysis. Washington, DC, National Aeronautics and Space Administration. (NASA SP-511.)

Goosse, H. and Th. Fichefet. 1999. Importance of ice- ${ }^{-}$ocean interactions for the global ocean circulation: a model study. 7. Geophys. Res., 104(C10), 23,337-23,355.

Goosse, H., E. Deleersnijder, Th. Fichefet and M. H. England. 1999. Sensitivity of a global coupled ocean-sea ice model to the parameterization of vertical mixing. 7. Geophys. Res., 104(C6), 13,681-13,695.
Häkkinen, S. 1993. An Arctic source for the Great Salinity Anomaly: a simulation of the Arctic ice- ocean system for 1955-1975. 7. Geophys. Res., 98(C9), 16,397-16,410.

Hilmer, M. and T. Jung. 2000. Evidence for recent change in the link between the North Atlantic Oscillation and Arctic sea ice export. Geophys. Res. Lett., 27(7), 989-992.

Holland, M. M. and J. A. Curry. 1999. The role of physical processes in determining the interdecadal variability of central Arctic sea ice. 7 . Climate, 12(11), 3319-3330.

Johannessen, O. M., E. V. Shalina and M.W. Miles. 1999. Satellite evidence for an Arctic sea ice cover in transformation. Science, 286(5446), 1937-1939.

Kalnay, E. and 21 others. 1996. The NCEP/NCAR 40-year reanalysis project. Bull. Am. Meteorol. Soc., $77(3), 437-471$.

Kwok, R. and D. A. Rothrock. 1999. Variability of Fram Strait ice flux and North Atlantic Oscillation. 7. Geophys. Res., 104(C4), 5177-5189. (Erratum: 104(C10), 2000, p. 23,615.)

Levitus, S. 1982. Climatological atlas of the world ocean. Rockville, MD, U.S. Department of Commerce. National Oceanic and Atmospheric Administration. (NOAA Professional Paper 13.)

Maslanik, J. A., M. G. Serreze and R. G. Barry. 1996. Recent decreases in Arctic summer ice cover and linkages to atmospheric circulation anomalies. Geophys. Res. Lett., 23(13), 1677-1680.

Morales Maqueda, M. A., A. J. Willmott and M. S. Darby. 1999. A numerical model for interdecadal variability of sea ice cover in the Greenland-Iceland-Norwegian Sea. Climate Dyn., 15(2), 89-113.

Mysak, L. A. and S. A. Venegas. 1998. Decadal climate oscillations in the Arctic: a new feedback loop for atmosphere-ice- ${ }^{-}$ocean interactions. Geophys. Res. Lett., 25(19), 3607-3610.

Opsteegh, J. D., R. J. Haarsma, F. M. Selten and A. Kattenberg. 1998. ECBILT: a dynamic alternative to mixed boundary conditions in ocean models. Tellus, 50A (3), 348-367.

Polyakov, I. V., A.Yu. Proshutinsky and M. A. Johnson. 1999. The seasonal cycles in two regimes of Arctic climate. f. Geophys. Res., 104(C11), 25,761-25,788.

Proshutinsky, A.Yu. and M. A. Johnson. 1997. Two circulation regimes of the wind-driven Arctic Ocean. F. Geophys. Res., 102(C6), 12,493-12,514.

Rothrock, D. A., Y. Yu and G. A. Maykut. 1999. Thinning of the Arctic seaice cover. Geophys. Res. Lett., 26(23), 3469-3472.

Schmitz, W. J. 1995. On the interbasin-scale thermohaline circulation. Reviews of Geophysics, 33(2), 151-173.

Selten, F. M., R. J. Haarsma and J. D. Opsteegh. 1999. On the mechanism of North Atlantic decadal variability. F. Climate, 12(7), 1956-1973.

Skeie, P. 2000. The coupling between cold air outbreaks over the Nordic Seas and Siberian warm months. Geophys. Res. Lett., 27(16), 2569-2571.

Slonosky, C. S., L. A. Mysak and J. Derome. 1997. Linking Arctic sea-ice and atmospheric circulation anomalies on interannual and decadal timescales. Atmosphere-Ocean, 35(3), 333-336.

Terray, L., S. Valcke and A. Piacentini. 1998. OASIS 2.2, Ocean Atmosphere Sea Ice Soil user's guide and reference manual. Toulouse, Centre Européen de Recherche et de Formation en Calcul Scientifique Avancé (CERFACS). (Tech. Rep. TR/CGMC/98-05.)

Thompson, D.W. J. and J.W. Wallace. 1998. The Arctic Oscillation signature in the wintertime geopotential height and temperature fields. Geophys. Res. Lett., 25(9), 1297-1300.

Tremblay, L.-B. and L. A. Mysak. 1998. On the origin and evolution of seaice anomalies in the Beaufort-Chukchi Sea. Climate Dyn., 14(6), 451-460.

Van Dorland, R., P. Stammes, A. A. M. Holtslag and W. Kohsiek. In press. A longwave radiative transfer scheme for climate modelling and its evaluation with surface observations at Cabauw. Quarterly fournal of the Royal Meteorological Society.

Walsh, J. E. and C. M. Johnson. 1979. Interannual atmospheric variability and associated fluctuation in Arctic sea ice extent. 7. Geophys. Res., 84(C11), 6915-6928.

Weatherly, J.W., B. P. Briegleb, W. G. Large and J. A. Maslanik. 1998. Sea ice and polar climate in the NCAR CSM. f. Climate, 11(6), 1472-1486.

Yi, D., L. A. Mysak and S. A. Venegas. 1999. Decadal-to-interdecadal fluctuations of Arctic sea-ice cover and the atmospheric circulation during 1954-1994. Atmosphere-Ocean, 37(4), 389-415. 